\title{
Example-Based Learning: Integrating Cognitive and Social-Cognitive Research Perspectives
}

\author{
Tamara van Gog • Nikol Rummel
}

Published online: 8 May 2010

(C) The Author(s) 2010. This article is published with open access at Springerlink.com

\begin{abstract}
Example-based learning has been studied from different perspectives. Cognitive research has mainly focused on worked examples, which typically provide students with a written worked-out didactical solution to a problem to study. Social-cognitive research has mostly focused on modeling examples, which provide students the opportunity to observe an adult or a peer model performing the task. The model can behave didactically or naturally, and the observation can take place face to face, on video, as a screen recording of the model's computer screen, or as an animation. This article reviews the contributions of the research on both types of example-based learning on questions such as why examplebased learning is effective, for what kinds of tasks and learners it is effective, and how examples should be designed and delivered to students to optimize learning. This will show both the commonalities and the differences in research on example-based learning conducted from both perspectives and might inspire the identification of new research questions.
\end{abstract}

Keywords Worked examples · Modeling $\cdot$ Social learning $\cdot$ Cognitive load Instructional design

Cognitive load theory (Sweller 1988, this issue; Sweller et al. 1998; Van Merriënboer and Sweller 2005) has emphasized the evolutionary importance of learning by observing and/or imitating what other people do, say, or write (Sweller 2004; Sweller and Sweller 2006) and so has Bandura's $(1977,1986)$ social learning theory. Both argue that it would be

T. van Gog $(\triangle)$

Institute of Psychology, Erasmus University Rotterdam, P.O. Box 1738, 3000 Rotterdam,

The Netherlands

e-mail: vangog@fsw.eur.nl

N. Rummel

Institute of Psychology, University of Freiburg, Freiburg im Breisgau, Germany

N. Rummel

Institute of Education, Ruhr-Universität Bochum, Bochum, Germany 
impossible (not to mention quite dangerous) for a human being to discover by one's own experience the vast amounts of knowledge that our ancestors developed over thousands of years. It is much more efficient to borrow this knowledge from others and reorganize it to fit in with one's existing knowledge and use it to one's own purposes (the "borrowing and reorganizing" principle; Sweller and Sweller). Not surprisingly, therefore, both theories have developed research lines on different ways of learning from others. What is surprising, however, is that these lines of research tend to be quite separated and not refer to each other very much. Cognitive load theory (as well as other cognitive theories such as adaptive control of thought - rational; Anderson 1993) has focused primarily on the effects of learning by studying worked examples as opposed to learning by problem solving. It has paid little attention to investigating the effects of learning by observing others directly ("modeling"), which has mainly been studied from a social-cognitive perspective (Bandura 1977, 1986; Collins et al. 1989) and which we will refer to as learning from "modeling examples" from here on (cf. Van Merriënboer 1997).

In contrast to modeling examples in which a problem-solving or performance procedure is demonstrated to a learner, a worked example provides students with a written account of how a problem should be or can be solved: Next to a description of the "givens" and the goal that are provided in conventional problems, worked examples additionally provide the worked-out solution steps that are to be taken to reach the goal (Sweller and Cooper 1985). One could argue that studying worked examples is a type of observational learning though. Both Sweller (2004; Sweller and Sweller 2006) and Bandura (1977, 1986) mention the use of symbolic models in words and images as an important means for simultaneously sharing one person's knowledge with large groups of "observers" (including future generations). Moreover, observational learning of cognitive tasks requires the model to somehow externalize their cognitive actions, for example, by thinking aloud, or writing down the actions, or they will not be observable for the learner (Collins et al. 1989). Therefore, in this sense, studying worked examples would qualify as a kind of observational learning.

Indeed, as we will show, there are many commonalities in (research on) learning from worked examples and modeling examples, although there are also some important differences. In this article, we will review the contributions of the research on both types of example-based learning on understanding why example-based learning is effective, for what kinds of tasks and learners it is effective, and how examples should be designed and delivered to students to optimize learning. We will also address how the commonalities and differences might inspire the identification of new research questions drawing on both theoretical perspectives.

\section{Why Is Example-Based Learning Effective?}

Research on studying worked examples has consistently shown that for novice learners, instruction that relies more heavily on studying worked examples than on problem solving is more effective for learning, as well as more efficient in that better learning outcomes are often reached with less investment of time and effort during acquisition (for reviews, see Atkinson et al. 2000; Sweller et al. 1998). This is referred to as the "worked example effect" (Sweller et al.), and this effect has been explained in terms of the different cognitive processes evoked by problem solving and example study. Instruction that consists mainly of solving conventional problems forces novices to resort to weak problem-solving strategies such as means-ends analysis, in which learners continuously search for operators to reduce the difference between the current problem state and the goal state (Sweller 1988). This 
imposes a high load on working memory but is not effective for learning: Even though such weak strategies may allow learners to succeed in solving the problem eventually (i.e., performance), they have been shown to contribute very little to learning, that is, to building a cognitive schema of how such problems should be solved. Worked examples prevent the use of such weak problem-solving strategies, allowing the learner instead to devote all the available cognitive capacity to studying the worked-out solution procedure (i.e., the relationship between problem states and operators) and constructing a cognitive schema for solving such problems (Sweller; Sweller et al.). Research has shown that worked examples can be used as an analogy for problem solving, either by being able to refer to the physical examples during problem solving (e.g., Reed et al. 1994) or by mentally referring back to the memory of a previously studied example. Moreover, what is learned from worked examples can go beyond the specific problem-solving procedure that was shown: general rules can be abstracted from the examples (e.g., Anderson and Fincham 1994; Anderson et al. 1997), which enables students not only to solve similar problems but also transfer problems for which (part of) the solution procedure has to be adapted (see, e.g., Cooper and Sweller 1987; Paas 1992; Paas and Van Merriënboer 1994).

One criticism of research on the worked example effect is that the control condition usually involves problem solving without any instructional support whatsoever (Koedinger and Aleven 2007). Recent studies have shown, however, that adding worked examples to tutored problem-solving environments (worked examples: Schwonke et al. 2009; videobased modeling examples: McLaren et al. 2008) or realistic mathematics methods (Van Loon-Hillen et al. in press) can also enhance learning, reduce acquisition time, or both. In addition, worked examples have been found to be more effective for learning than discovery learning (Tuovinen and Sweller 1999) and problem solving with a more general level of guidance provided by process steps (i.e., a description of the steps to be taken, but the steps are to be worked out by the learner; Nievelstein et al. 2010; Van Gog et al. 2006).

The effectiveness of modeling examples, on the other hand, is not usually explained in comparison with other types of learning but more in terms of the general cognitive processes that need to take place for observational learning to be effective. Bandura (1977, 1986) postulated that observers acquire a cognitive (symbolic) representation (cf. cognitive schema) of the model's behavior that outlasts the modeling situation and thus enables learners to exhibit the observed and novel behavior at later occasions. This is an important extension of earlier research on imitation in the behaviorist tradition (Miller and Dollard 1941) and implies that observational learning can occur without imitation taking place. In acquiring this representation, it is, first and foremost, required that the learner pays attention to the relevant aspects of the modeled behavior, and "selective attention is, therefore, one of the crucial subfunctions in observational learning" (Bandura 1986, p. 51). The learner's attention is influenced both by the salience of those aspects and by the characteristics of the model (we will return to this issue below, in the section on example design). Secondly, the attended information needs to be retained in memory, which requires encoding this information. Like Sweller and colleagues (Sweller and Sweller 2006; Sweller et al. 1998), Bandura stresses that this is not a one-on-one mapping but rather a constructive process during which information is actively (re)organized and integrated with the existing knowledge of the learner. Rehearsal, either mentally or physically, also plays an important role in retention, as well as in improvement of performance. However, learners may not always be able to produce the observed behaviors themselves. Whether or not they are able to do so depends on the quality of the cognitive representation they have acquired and on the extent to which they master the component skills. Finally, whether or not the learner will actually exhibit the behavior learned through observation is determined by motivational processes. 
In sum, both cognitive and social-cognitive theories stress the importance of constructing appropriate cognitive representations to guide later performance by the learner. The nature of the attentional processes, however, may be an important difference between worked examples and modeling examples. Worked examples usually present a written, "ideal" or "didactical" procedure. In other words, it reflects the way in which students should learn to solve a particular problem, not necessarily how another person would actually solve it (e.g., individuals with low expertise might make errors; individuals with more expertise tend to skip steps: Blessing and Anderson 1996; Kalyuga and Sweller 2004). As a consequence, all the steps that are presented are relevant for the learner to attend to, and because it is written, little distracting information is present. In modeling examples, however, there may be a great deal of distracting information. Regardless of whether the performance of the model is observed face to face, on video, as a recording of the model's screen (McLaren et al. 2008), or as an animation in which the model could be represented by an animated agent (Wouters et al. 2008), there is much more opportunity for learners to attend to irrelevant details (e.g., the model's clothes, tone of voice, and salient but irrelevant objects present in the environment or on the screen) than in worked examples. Moreover, the model could be a teacher or an expert who is behaving didactically (e.g., Schunk 1981; Simon and Werner 1996), in which case - as in worked examples - the demonstrated steps might all be relevant to incorporate in the cognitive schema, but the model could also be a peer student with a lower, equal, or higher level of performance than the learner, in which case the demonstrated procedure may contain errors (e.g., Braaksma et al. 2002; Schunk and Hanson 1985). Below, we will discuss the consequences the difference in attentional processes has for the design of examples, but first, we will address the questions of for what kinds of tasks and learners example-based learning is effective.

\section{For What Kinds of Tasks Is Example-Based Learning Effective?}

The majority of research on worked examples has been conducted using highly structured cognitive tasks in domains such as algebra (e.g., Carroll 1994; Cooper and Sweller 1987; Mwangi and Sweller 1998; Sweller and Cooper 1985), statistics (e.g., Paas 1992; Quilici and Mayer 1996), geometry (e.g., Catrambone 1995, 1996; Paas and Van Merriënboer 1994; Schwonke et al. 2009; Tarmizi and Sweller 1988), or physics (e.g., Kalyuga et al. 2001; Reisslein et al. 2006; Van Gog et al. 2006, 2008; Ward and Sweller 1990). However, several recent studies have shown that worked examples can also be effective with less structured cognitive tasks such as learning how to apply an instructional design model (Hoogveld et al. 2005), learning argumentation skills (Schworm and Renkl 2007), learning to construct concept maps (Hilbert and Renkl 2009), learning to recognize designer styles (Rourke and Sweller 2009), or learning to reason about legal cases (Nievelstein et al. 2010).

Like worked examples, modeling examples have also been used to teach highly structured cognitive skills such as math, although the focus in those studies was not only on how well students learned to solve math problems but also on how students' self-efficacy was influenced by modeling examples, which is an important difference with worked examples research (e.g., Schunk 1981; Schunk and Hanson 1985). Modeling examples have been used more often, however, to teach less structured skills such as writing (e.g., Braaksma et al. 2002, 2004; Couzijn 1999; Zimmerman and Kitsantas 2002), assertive communication (Baldwin 1992; Decker 1980), or collaboration (Rummel and Spada 2005; Rummel et al. 2009). In addition, they have been successfully used for teaching metacognitive skills such as self-regulation (e.g., Kitsantas et al. 2000; Zimmerman and 
Kitsantas 2002) or (self-) assessment (Van Gog et al., in press). In contrast to worked examples, modeling examples are also highly suitable and are widely used to teach (psycho)motor skills (see, e.g., Blandin et al. 1999; Wright et al. 1997). Research on the mirror neuron system has provided important insights into the underlying mechanisms of observational learning of motor skills, by showing that the same neural circuits that are involved in executing a motor action oneself, also respond to observing someone else executing that action (for a review, see Rizzolatti and Craighero 2004). It has also been shown that the neural circuits that are active when executing and observing motor actions respond when hearing sentences that describe such actions (Tettamanti et al. 2005) or when imagining performing such actions without actual movement (Grèzes and Decety 2001; Hurley 2008). An interesting open question is to what extent a similar mechanism might underlie learning cognitive skills from worked or modeling examples (see also Van Gog et al. 2009b).

Recent studies that have investigated example-based learning in the context of collaborative learning yielded somewhat inconsistent results (Chi et al. 2008; Craig et al. 2009; Kirschner et al. 2010; Rummel and Spada 2005; Rummel et al. 2009). Kirschner et al. showed that learning from "traditional" worked examples on a highly structured task (heredity problems) was more effective when done individually than collaboratively, whereas learning by solving conventional problems was more effective when done collaboratively than individually. They explained this in terms of the amount of cognitive load involved: because worked examples impose less cognitive load on individual learners than problem solving, the learning task can easily be performed by the individual, whereas problem solving imposes higher cognitive load, which can be shared by group members in collaborative learning situations (see also Kirschner et al. 2009). In contrast, Chi et al. showed that collaboratively observing a tutoring session and solving the same problems as the tutee in that session was more effective for learning than individual observation. Rummel and Spada, and Rummel et al. presented learners with modeling examples showing a collaborative process and showed that collaborative learning from examples was more effective than collaborative problem solving for the joint problem-solution and for acquiring collaboration skills. It thus seems that the type of task for which examples are used plays an important role in whether or not collaborative learning from the examples is effective.

Renkl et al. (2009) refer to examples that convey both task topic knowledge (e.g., biology, math) as well as skills such as argumentation, collaboration, or self-regulation as double-content examples and to examples that additionally convey strategic or heuristic knowledge as triple-content examples. Because the cognitive load imposed by such double or triple-content examples is much higher (i.e., there are more interacting information elements that need to be processed in working memory; Sweller et al. 1998), Renkl et al. argue that it is best to have learners focus their attention on only one of the content levels.

In sum, example-based learning is effective for learning a wide range of tasks and skills. There are some factors that can decrease or increase the effectiveness of examples for learning, though, such as learner characteristics and example design and delivery, which will be discussed in the following sections.

\section{For What Kinds of Learners Is Example-Based Learning Effective?}

Learning from worked examples has been studied in a wide variety of educational settings, ranging from primary school to university students and vocational/business training 
programs. Even though worked examples can be effectively used at various educational levels, there are certain learner characteristics that may influence the effectiveness of examples, the most important one being prior knowledge of the task. Above, in explaining the worked example effect, it was already indicated that studying worked examples is more effective than problem solving for novices. Research on the "expertise reversal effect" has shown that students' level of prior knowledge has an important influence on the effectiveness of instructional formats. Formats that are effective for learning when students have little or no prior knowledge may be less effective or ineffective for students with more knowledge and vice versa (Kalyuga 2007; Kalyuga et al. 2003). The high level of instructional guidance provided by worked examples, which fosters learning when no cognitive schemata are available yet, has been shown to be ineffective or even detrimental for learning when students have already developed cognitive schemata that can guide their problem solving (Kalyuga et al. 2001; Kalyuga and Sweller 2004). This can also occur when knowledge is acquired during the instruction phase, so it is important to dynamically adapt the amount of guidance provided to the learner's level of knowledge (Kalyuga and Sweller 2004; see also paragraph on "fading" in the section on example delivery).

Although little research has been conducted in this area, another learner characteristic that may influence the effectiveness of worked examples is working memory capacity. Because studying worked examples tends to reduce cognitive load compared to problem solving (e.g., Nievelstein et al. 2010; Paas 1992; Paas and Van Merriënboer 1994; Van Gog et al. 2006), it may be even more effective for learners who have lower working memory capacity. Lower working memory capacity has been associated with certain learning disabilities and may also occur due to effects of aging. Van Gerven et al. (2002) showed that elderly participants benefitted relatively more from example study compared to problem solving than young participants.

The effects of observational learning through modeling have also been studied with different kinds of learners in a wide variety of (educational) settings. While most research has focussed on children, a number of studies have been conducted with adults, showing, for example, that modeling can increase the use of protective equipment in the workplace (Olson et al. 2009), can guide the selection of an effective memory strategy for college students (McGivern et al. 1986), and can improve writing and self-regulatory skills (Zimmerman and Kitsantas 2002). Interestingly, modeling is also effective for children with "abnormal" cognitive development. Such studies have shown that peer modeling, but not adult modeling, is effective for educable mentally retarded children (e.g., Barry and Overman 1977) and autistic children (e.g., Charlop et al. 1983).

Bandura (1986) has also noted the important mediating role of prior knowledge in learning from modeling examples. For instance, he emphasizes that modeled behavior that is too complex for the learner may result in fragmentary learning. In addition, he indicates that people with more expertise may recognize subtle aspects of performance that are not noticed by novices and that novices may have difficulty detecting errors because the ability to do so also relies on prior knowledge (see also Dunning et al. 2003), which may have the undesirable effect that novices may engage in cognitive/physical rehearsal of faulty behavior displayed by the model. Next to prior knowledge, another important learner characteristic that has been extensively studied in research on modeling examples is students' self-efficacy (e.g., Schunk and Hanson 1985), which may differentially affect the effectiveness of different types of models (see also the paragraph on model-observer similarity in the section on example design). Some research has also addressed variables such as self-esteem and locus of control as mediating learner characteristics for observational learning (e.g., Halpin et al. 1979). Fouts and Click (1979) found that 
extroverted children learned more than introverted children across three modeling conditions. Next to those learner characteristics, design characteristics of the examples also have the potential to reduce or enhance their effectiveness for learning.

\section{How Should Examples Be Designed to Optimize Their Effectiveness?}

Following the early studies on worked examples by Sweller and Cooper (1985) and Cooper and Sweller (1987), it was soon discovered that studying worked examples was not always more effective for learning than problem solving and that the design of the examples played a crucial role in this (Tarmizi and Sweller 1988). Research on this issue led to important design guidelines, such as avoid split-attention by integrating mutually referring information sources such as text and picture/diagram (Tarmizi and Sweller; this can also be done by providing spoken rather than written text with the pictorial information in the example; Mousavi et al. 1995) and avoid redundancy, that is, multiple sources of information should only be presented when they are both necessary for comprehension; when they can be easily understood in isolation, one of the sources is redundant and should be left out (see Chandler and Sweller 1991).

In addition, several other design measures have been investigated that might further enhance the effectiveness of worked examples They do so primarily by stimulating more active processing of the examples or emphasizing important aspects of the procedure, which helps students not only to learn the problem-solving procedure but also to understand the underlying structure and rationale, which is necessary to be able to solve slightly novel problems (i.e., transfer). For example, students might be required to complete steps in partially worked-out examples (e.g., Paas 1992; Van Merriënboer et al. 2002). In mathematics or statistics worked examples, it has been shown that learning can be fostered by making subgoals explicit through labeling or visually isolating sets of steps (e.g., Catrambone 1995, 1996), by comparing examples of different (representations of) solution methods (Große and Renkl 2006; Rittle-Johnson et al. 2009), or by using conceptually oriented equations rather than computationally oriented equations (e.g., Atkinson et al. 2003a). Active processing and understanding can also be fostered by instructing students to self-explain the principles behind the worked-out solution steps (e.g., Chi et al. 1989; Renkl 1997, 2002). However, a precondition is that students are capable of providing high quality self-explanations, which is not always the case (see Chi et al. 1989; Lovett 1992; Renkl 1997). If this precondition is not met, providing high quality instructional explanations may enhance learning from examples (Lovett 1992). In providing instructional explanations, however, one should take into account that these may become redundant relatively quickly, at which point they need to be faded out or may start to hamper learning (Van Gog et al. 2008). Self-explanations and instructional explanations have also been studied with modeling examples. Decker $(1980,1984)$ has shown the effectiveness of instructional explanations (he calls them "learning points") in video-based modeling examples that conveyed complex social skills such as conflict management skills. Rummel et al. (2009) incorporated instructional explanations in modeling examples and asked students to collaboratively explain after studying the example, which yielded better results than observing the modeling example without these additional instructional and self-explanations.

Some studies on worked examples have deviated from presenting a didactical solution and have used erroneous examples with an instruction for students to find and fix the errors (e.g., Große and Renkl 2007) or with additional feedback (e.g., Kopp et al. 2008) to stimulate students to process the examples more deeply. As mentioned before, modeling 
examples that show a model's natural rather than didactical behavior are likely to contain errors and also often show the correction of those errors by the model. Baldwin (1992) investigated the use of only positive (or correct) models or a combination of positive and negative (or incorrect) modeling examples on assertive communication. The combination of positive and negative models had a positive effect on trainees' transfer performance 4 weeks later but not on immediate behavioral reproduction; trainees who had observed only positive models performed better on the behavioral reproduction task. Große and Renk1 used a similar design, but with worked examples on probability calculation, and showed an interaction with students' prior knowledge: Providing both correct and incorrect solutions fostered far transfer performance for students with more prior knowledge, whereas correct solutions only worked better for students with low prior knowledge. Kopp et al. showed that the acquisition of diagnostic knowledge from worked examples was fostered when erroneous examples were provided in combination with elaborated feedback, but when only correct response feedback was provided, erroneous examples were detrimental for learning. Using modeling examples, Blandin and Proteau (2000) showed that observation of a model practising a motor skill allowed the observer to develop mechanisms for error detection and correction similar to those developed through physical practice. Furthermore, Badets et al. (2006) showed that giving an observer infrequent feedback (i.e., 50\%, on every other trial) on the correctness of the model's performance enhanced the observer's own performance, as well as the observer's ability to detect errors both in the model's and his/her own performance, compared to feedback given on every trial (i.e., 100\%). These findings indicate that the role of feedback in enhancing learning is similar in learning by doing and observational learning situations. An interesting finding from brain research for modeling examples (and maybe also worked examples) showing errors is that an event-related potential component called error-related negativity is found when we make a mistake ourselves and also when we observe someone making a mistake (Van Schie et al. 2004). Therefore, the same neural circuits are involved not only in performing actions by oneself and observing others perform those actions (Rizzolatti and Craighero 2004) but also in monitoring self-executed and observed actions.

The imagination effect shows that imagining or-as Bandura (1986) calls itcognitively rehearsing the procedure presented in examples enhances learning compared to studying only - at least for students with prior knowledge. For students without prior knowledge, imagining has detrimental effects, and for them, studying the procedure is more effective (Cooper et al. 2001; Ginns et al. 2003; note that this is another instance of the expertise reversal effect; Kalyuga 2007). Bandura reviews findings that cognitive rehearsal of the observed behavior can enhance learning, provided that it is accurate and indicates that the effect is more likely to be obtained with tasks that rely on more extensive cognitive processing (see also Driskell et al. 1994; Feltz and Landers 1983). This was also shown by Leahy and Sweller $(2005,2008)$ who demonstrated that the imagination effect is more likely to be obtained with complex materials (i.e., materials that are high in intrinsic load, containing many interacting information elements; Sweller et al. 1998). As mentioned earlier, brain research has shown that imagining performance of motor tasks activates the same neural circuits as performing or observing those tasks (e.g., Hurley 2008).

Using modeling examples based on screen recordings from participants in problemsolving conditions (yoked design), Osman (2008) showed that the goal-free effect applies to example-based learning as well. The goal-free effect has been studied in cognitive load research with problem-solving tasks (e.g., Ayres 1993; Paas et al. 2001; Sweller and Levine 1982) and shows that learning is enhanced when students are not provided with a specific goal during problem solving. Providing students with no or a nonspecific goal is assumed 
to prevent the use of means-ends analysis, thereby leading to better learning (Sweller and Levine 1982). Apparently, this benefit applies not only to the performer but also to the observer's learning (Osman).

There are a number of other design characteristics that do not play a role in worked examples but are relevant for modeling examples, such as model-observer similarity in sex, age, competence, or background, of which the first three have been studied most (for a review, see Schunk 1987). As Schunk notes, "similarity serves as an important source of information for gauging behavioral appropriateness, formulating outcome expectations, and assessing one's self-efficacy for learning or performing tasks" (p. 149). One source of similarity is sex, but results from studies concerning similarity in sex between models and observers are inconclusive. For instance, Bandura and Kupers (1964) found that neither the sex of the model, nor the sex of the observing child, nor the congruence in the sex of model and observer showed an influence on learning. In contrast, in a study by Bandura et al. (1963), sex did play an important role for learning. The decisive difference between the two studies was the content of the modeled behavior: In the former study, children observed and learned to self-reinforce for performance in a game, whereas in the latter study, children observed models perform aggressive behaviors toward a doll, so ideas about sexappropriateness or stereotyping played a role in the latter. More recently, Weeks et al. (2005) found that when healthy elderly women observed physiotherapists demonstrating exercises, participants provided higher ratings of self-efficacy when their model was a female as well, but for men, the sex of their model did not prove to be of influence.

A second source of similarity is age. With children who were low achieving in mathematics, Schunk and Hanson (1985) showed that peer models were more effective than adult models (who were more effective than no models) in enhancing self-efficacy and learning outcomes. With educable mentally retarded children, Barry and Overman (1977) also found peer models to be more effective. Other studies, however, have shown no differences due to similarity in age (see also Weeks et al. 2005), and Schunk suggests that (perceived) competence of the model and self-efficacy may interact with similarity in age to influence model preference and learning. The model's (perceived) competence plays a role in that competent models lead to better learning than incompetent models, but as a standard for comparison or self-evaluation, equally competent models seem to be preferred (see Schunk). This is also supported by the above-cited study by Bandura and Kupers (1964): they found adult models to be more effective for children's observational learning than peers.

Related to model competence, an important factor seems to be whether the model is a mastery model displaying faultless performance or a coping model whose performance includes errors that are corrected and expressions of uncertainty that is gradually reduced. Schunk and Hanson (1985) found no differential effects of a peer coping or a peer mastery model (both were better than an adult model, which was better than no model), but Schunk et al. (1987) showed that coping peer models were more effective than mastery peer models and that children who observed coping peer models judged themselves to be more similar in competence to the models. Braaksma et al. (2002) gave learners in two observational learning conditions both good and weak peer models. The conditions differed in instruction, with one group being asked to focus on the weak model (which model did less well? Explain briefly what this model did worse) and the other on the good model (which model did well? Explain briefly what this model did well). They found that weak learners learned more from focusing on weak models, whereas better learners learned more from focusing on good models. George et al. (1992) investigated self-efficacy and muscular endurance of nonathletic female students after watching videotapes of a model performing a leg- 
extension endurance task. Participants who watched nonathletic models reported higher self-efficacy and extended their legs significantly longer than those watching athletic models (sex of the model did not have an effect on either measure).

Related to the issue of model competence is the degree of difference in model and observer expertise. Naturally (i.e., nondidactically) behaving experts may not be the best models for cognitive tasks because they have often automated their task performance to a large extent. This not only means that they perform very fast and tend to skip steps (Blessing and Anderson 1996; Kalyuga and Sweller 2004), which might make it difficult for students to see or follow what the model is doing but also means that the model may have difficulty verbalizing what $\mathrm{s} /$ he is doing because the performance does not require controlled processing (Feldon 2007). It has also been suggested that the level of abstraction of instructions provided by experts may pose problems for novices' understanding and that instructions provided by somewhat advanced individuals led to better task performance (Hinds et al. 2001). On the other hand, the higher level of abstraction in expert instructions seemed to be more beneficial for solving novel tasks (i.e., transfer; Hinds et al. 2001). Moreover, expert models might be more effective for advanced students to learn from, as they might be less bothered by the skipping of steps, as their own knowledge base is closer to that of the expert and they are more likely to know what the relevant aspects of performance are that they need to attend to (cf. Bandura 1986). Therefore, an interesting question for future research is whether the level of model expertise affects learning and whether it has differential effects depending on learner expertise. A study by Boekhout et al. (in press) showed that both first and second year physiotherapy students learned to take patients' histories better from expert worked examples than from advanced student worked examples. However, this is not a task where knowledge automation and abstraction plays a large role, so further research would be required with tasks in which experts might use more abstract terms than advanced students, such as, for instance, in recalling or reasoning about medical cases (e.g., Rikers et al. 2000).

Finally, an extreme form of model-observer similarity is attained in self-modeling, in which children watch (edited) videotapes of themselves performing the model behavior, which has proven highly effective (and as effective as peer modeling) in promoting academic and behavioral skills (Schunk and Hanson 1989; for a review, see Hitchcock et al. 2003).

In modeling examples that consist of screen recordings with spoken text (e.g., McLaren et al. 2006, 2008; Rummel and Spada 2005; Rummel et al. 2009; Van Gog et al. 2009a) or in animated modeling examples with a pedagogical agent and spoken text (e.g., Atkinson 2002; Wouters et al. 2009), issues of perceived similarity to the model may also arise because of students' associations with the speaker's voice (e.g., sex, age). Kim (2007) found that similarity in competence also played an important role when students learned from an anthropomorphized pedagogical agent. Academically, strong students recalled more after working with a high-competent agent, while academically weak students profited more from a low-competent agent. Therefore, in these kinds of examples, even when they show a didactical procedure, model-observer similarity may play a role as well. This should be further investigated and, if necessary, be taken into account in the design of the examples.

Moreover, there are some design principles that multimedia research has shown to enhance (perceived) social presence and thereby lead to better learning: the personalization, voice, and image principles (Mayer 2005). The personalization principle means that people learn more deeply when words in a multimedia presentation are in conversational rather than formal style (e.g., using "I" and "you"), the voice principle that people learn more deeply when words in a multimedia message are spoken in a standard-accented human voice rather than a machine voice or foreign-accented human voice, and the image principle 
that people do not necessarily learn more deeply when the speaker's image is present on the screen (Mayer 2005). The image principle seems to suggest that visual presence of the model is not strictly necessary for learning to be effective, which seems to be good news for screen-recording modeling examples. In fact, having the model present live or on video might have adverse effects on the learner's attention. On the one hand, eye tracking research has shown that our gaze allocation is socially directed, that is, we tend to follow another person's gaze (which is often used in magic tricks to misdirect observers' attention; Kuhn et al. 2008). On the other hand, eye tracking research has shown that we tend to look primarily at the person's face (as much as $95 \%$ of the time in face-to-face situations and $89 \%$ of the time on video), rather than at his or her gestures, for example (Gullberg and Holmqvist 2002). Although this might be different in learning situations than in "natural" situations, a study by Louwerse et al. (2009) on humanoid animated agents that are often used in multimedia learning materials showed that students tend to look at faces of those agents as they would at real humans, that is, they look primarily at the agent's face (study 1) or looked primarily at the agent's face when it spoke (Study 2). This might imply that in modeling examples in which the model is present, the learner's visual attention may be drawn toward the model, especially when s/he is speaking, rather than to the task aspects the model is talking about.

Finally, there are some guidelines from research on the effectiveness of animations that might be relevant for the design of screen recording or animated modeling examples. Because the information in screen recordings or animated modeling examples is often transient, students' understanding might be compromised if they do not attend to the right information at the right time because it can be gone the next moment. When the verbal explanation provided by the model is not sufficient to guide students' attention to the right information at the right time, other means of doing so are available, such as cueing (i.e., perceptually highlighting) certain information elements (for a review, see De Koning et al. 2009) or showing students where the model is looking by displaying the model's eye movements superimposed on the video (Van Gog et al. 2009a, b). The transience of information is also an important difference between worked examples and modeling examples. Worked examples generally provide learners with a complete overview of the procedure, whereas modeling examples may either build up that overview step by step (i.e., each step that is worked out remains visible, while the model works on the next step; e.g., McLaren et al. 2008), in which case, at the end, a complete worked example is essentially available or show only one step at a time that makes way for the next step (e.g., Spanjers, Wouters, Van Gog and Van Merriënboer in press; Wouters et al. 2009). In case of the latter, the transience of the information requires learners to maintain each presented step in working memory while attending to the step that is currently being executed and processing them in relation to each other. This is extremely cognitively demanding, especially for novice students, and might hamper learning (e.g., Ayres and Paas 2007). Segmenting such transient examples might help novices' learning because it gives them the necessary time to process information and/or makes them more aware of the structure of the problem-solving procedure (see Spanjers, Van Gog and Van Merriënboer in press).

\section{How Should Examples Be Delivered to Optimize Their Effectiveness?}

Although he stresses that observational learning can occur without immediate imitation taking place, Bandura (1986) also indicates that giving students the opportunity to practice the behavior themselves in between observations of modeling examples may foster learning 
because practice allows them to note deficiencies in their own performance, which may increase their attention to those aspects during a future observation of a model's performance. This is, in fact, the way in which the majority of studies on the worked example effect were designed: example-problem pairs were used, and these were shown to be more effective for learning than engaging in problem solving only (Carroll 1994; Cooper and Sweller 1987; Kalyuga et al. 2001; Kalyuga and Sweller 2004; Mwangi and Sweller 1998; Sweller and Cooper 1985), at least for low ability or low prior knowledge learners (Cooper and Sweller 1987; Kalyuga et al. 2001). Studies on modeling examples have also implemented this principle (e.g., Simon and Werner 1996). Sweller and Cooper (1985) stated that engaging in solving a similar problem immediately after example study may be more motivating for students because it is more active than studying another example would be. As far as we know, however, there are no empirical data yet that support this suggestion.

In line with the finding that imitation does not seem to be necessary for learning, worked examples research has demonstrated that studying examples only is also more effective for learning than engaging in problem solving only (Nievelstein et al. 2010; Van Gerven et al. 2002; Van Gog et al. 2006). In fact, it can be questioned whether the opportunity to practice indeed has added value for learning: A recent study found that both examples only and example-problem pairs were more effective than problem solving and problem-example pairs, and there was no significant difference between examples only and example-problem pairs (Van Gog et al. 2010).

Problem-example pairs allow for noting deficiencies in students' own performance, which may increase their attention to those aspects during example study, but in the study of Van Gog et al. (2010), problem-example pairs were less effective for learning than example-problem pairs and examples only and did not lead to better learning than problem solving only. A possible explanation is that students are very often unable to diagnose their own performance deficiencies (for a review, see Bjork 1999). The studies by Paas (1992) and Paas and Van Merriënboer (1994) are interesting in this respect. Their problem-solving conditions were given a worked example of the same problem as feedback when they did not succeed in solving a problem within a certain time or certain number of attempts. Therefore, the example was identical to the problem students had just attempted to solve, which would allow students to pay attention to the exact steps that proved to be problematic for them. Nevertheless, the examples conditions (Paas 1992: two examples, then a problem; Paas and Van Merriënboer 1994: examples only) were more effective than the problemsolving condition in which examples were given as feedback when the student could not solve the problem. This suggests that those novice learners were not able to use the examples as feedback effectively, presumably because they were not able to accurately diagnose their own performance deficiencies. The ability to do so seems to be related to one's knowledge of the tasks (Dunning et al. 2003), which novices lack. This fits with the findings of Reisslein et al. (2006), who found an interaction of example-problem pairs and problem-example pairs with learners' prior knowledge: Whereas low prior knowledge learners benefited most from example-problem pairs, high prior knowledge learners benefited most from problem-example pairs. In tutored problem solving, however, learners can request help immediately when they experience that they cannot solve a particular step, which is unproblematic for novices and, in this case, help consisting of annotated worked examples has been shown to be more efficient (equal test performance achieved in less learning time) than help consisting of hints (Ringenberg and VanLehn 2006).

An effective delivery strategy for cognitive tasks that takes into account the learner's developing knowledge of a task (which, as described previously, affects the effectiveness of 
worked examples) is the completion or fading strategy, in which completion problems with increasingly more steps for the learner to complete serve as a bridge between studying fully worked-out examples and problem solving (for a review, see Renkl and Atkinson 2003). Reisslein et al. (2006) found no overall differences between fading, problem-example pairs, and example-problem pairs, but Renkl et al. (2002) and Atkinson et al. (2003b) did find a fading strategy to be more effective than example-problem pairs, especially backward fading in which the last solution steps are omitted first in the completion problems.

Note that in motor learning, the effects of combinations of example study and practice may be very different. Shea et al. (2000) studied effects of physical practice only, observation (i.e., modeling examples) only, and no practice and found physical practice to be more effective than observational practice for retention, but there were no differences on transfer. However, in a second experiment, they showed that combined (alternating) physical practice and observation was more effective for transfer than physical practice only. Weeks and Anderson (2000) compared the effects of viewing 10 video-based modeling examples before practice, viewing one before practice and the others during practice (one every three attempts) and viewing five before practice and the others during (the first half of) practice (one every three attempts). The latter group attained the highest scores, followed by the all prepractice group.

Finally, another effective delivery strategy for worked examples (Paas and Van Merriënboer 1994), completion problems (Van Merriënboer et al. 2002), and modeling examples (Wright et al. 1997) is not presenting them in a typical blocked sequence by problem type or category (e.g., AAA-BBB-CCC-DDD), but in a random sequence (e.g., AC-D-B-B-C-A-D-A-B-D-C). Although random sequencing tends to increase cognitive load and decrease performance during training, it does lead to better learning and transfer outcomes, so this increase in cognitive load is due to processes that are germane or effective for learning. Presumably, a random sequence challenges learners to compare the different procedures associated with the different types of problems, which may help them, for example, to learn which problem features are relevant for a certain solution procedure and which are not, whereas in a blocked schedule, only one procedure has to be kept in mind during a block of tasks (Paas and Van Merriënboer).

\section{Conclusion}

This review, which was by no means exhaustive, has discussed studies on example-based learning conducted from a cognitive and social-cognitive perspective. Table 1 provides an overview of the commonalities and differences between both lines of research that we discussed. What stands out is the wide variety of tasks, contexts, and learners for which example-based learning can be effectively applied. While this is certainly a strength because it shows that example-based learning is a widely applicable method, the heterogeneity in the kinds of examples used, the tasks for which they are used, and the learners who participate in the studies also make it difficult to draw definitive conclusions about what works, when, and for whom. For example, in the studies by Braaksma et al. (2002) and Kim (2007), the weaker students learned more effectively from the weak models, whereas in the study by Große and Renkl (2007), only students with more prior knowledge benefited from erroneous examples. These studies differ on so many points, however, that it is hard to draw a conclusion about what might have caused the seemingly different findings. 
Table 1 Overview of the Most Prominent Commonalities and Differences Between Worked Examples and Modeling Examples Research as Discussed in This Article (i.e., Not Exhaustive)

\begin{tabular}{|c|c|c|}
\hline & Worked Examples & Modeling Examples \\
\hline Form & Text based & $\begin{array}{l}\text { Live observation } \\
\text { Observing a video of the model } \\
\text { Observing a screen-capture video } \\
\text { (model not visible) } \\
\text { Observing an animation }\end{array}$ \\
\hline Solution procedure/model & Ideal/didactical & $\begin{array}{l}\text { Didactical } \\
\text { Natural performance by peer/adult }\end{array}$ \\
\hline Type of task/skill & $\begin{array}{l}\text { Highly structured problems } \\
\text { Less structured problems/tasks }\end{array}$ & $\begin{array}{l}\text { Highly structured problems } \\
\text { Less structured problems/tasks } \\
\text { Social skills } \\
\text { Metacognitive skills } \\
\text { (Psycho)motor skills }\end{array}$ \\
\hline Type of learner & Primary school age to adult & Primary school age to adult \\
\hline $\begin{array}{l}\text { Learner characteristics, } \\
\text { effects of }\end{array}$ & $\begin{array}{l}\text { Prior knowledge } \\
\text { Aging }\end{array}$ & $\begin{array}{l}\text { Prior knowledge } \\
\text { Self-efficacy }\end{array}$ \\
\hline $\begin{array}{l}\text { Process/Outcome } \\
\text { measures }\end{array}$ & $\begin{array}{l}\text { Learning/retention } \\
\text { Transfer } \\
\text { Cognitive load } \\
\text { Time on task }\end{array}$ & $\begin{array}{l}\text { Learning/retention } \\
\text { Transfer } \\
\text { Self-efficacy }\end{array}$ \\
\hline Design, effects of & $\begin{array}{l}\text { Split-attention } \\
\text { Redundancy } \\
\text { Completing steps }\end{array}$ & $\begin{array}{l}\text { Model sex } \\
\text { Model age } \\
\text { Model competence (i.e., making } \\
\text { and/or correcting errors) }\end{array}$ \\
\hline & $\begin{array}{l}\text { Making subgoals explicit } \\
\text { Comparing procedures } \\
\text { Self-explanations } \\
\text { Instructional explanations } \\
\text { Finding and fixing errors } \\
\text { Imagining/cognitive rehearsal }\end{array}$ & $\begin{array}{l}\text { Self-explanations } \\
\text { Instructional explanations } \\
\text { Feedback on model performance } \\
\text { Imagining / cognitive rehearsal }\end{array}$ \\
\hline Delivery, effects of & $\begin{array}{l}\text { Ratio/alternation of examples } \\
\text { and problems } \\
\text { Fading from examples to } \\
\text { problems } \\
\text { Random sequencing }\end{array}$ & $\begin{array}{l}\text { Ratio/alternation of examples } \\
\text { and problems } \\
\text { Random sequencing }\end{array}$ \\
\hline
\end{tabular}

We hope that future research on example-based learning will draw on both perspectives to identify and address novel research questions. Studies using examples consisting of screen captures may allow for a particularly powerful combination of both approaches. For example, an ideal procedure can be shown, and when steps are built up consecutively (e.g., McLaren et al. 2008), the end result is a complete worked example. In addition, there are some design guidelines that have been identified in cognitive load and worked examples research that are relevant for the design of such examples as well (e.g., avoid split-attention, avoid redundancy) and so are principles from multimedia research. Finally, even though the 
model may not be visible in the screen capture, some characteristics identified in modeling examples, such as the model's age, sex, and performance (e.g., coping vs. mastery), might be relevant, as they might affect the results. Future studies from either perspective might also draw on the strong points of the other perspective. For example, research on worked examples might address effects of/on self-efficacy as a mediating or outcome variable or the effects of showing nondidactical procedures in examples (cf. Boekhout et al. in press), whereas research on modeling examples might address the effects of different design and delivery strategies identified as effective in worked examples research, as well as effects of modeling examples on cognitive load.

Acknowledgment This work is part of a research project by the first author that is funded by the Netherlands Organization for Scientific Research (Veni Grant 451-08-003). The authors would like to thank Michael Wiedmann for his help with finding some of the literature.

Open Access This article is distributed under the terms of the Creative Commons Attribution Noncommercial License which permits any noncommercial use, distribution, and reproduction in any medium, provided the original author(s) and source are credited.

\section{References}

Anderson, J. R. (1993). Rules of the mind. Hillsdale: Erlbaum.

Anderson, J. R., \& Fincham, J. M. (1994). Acquisition of procedural skills from examples. Journal of Experimental Psychology. Learning, Memory, and Cognition, 20, 1322-1340.

Anderson, J. R., Fincham, J. M., \& Douglass, S. (1997). The role of examples and rules in the acquisition of a cognitive skill. Journal of Experimental Psychology. Learning, Memory, and Cognition, 23, 932-945.

Atkinson, R. K. (2002). Optimizing learning from examples using animated pedagogical agents. Journal of Education \& Psychology, 94, 416-427.

Atkinson, R. K., Derry, S. J., Renkl, A., \& Wortham, D. (2000). Learning from examples: Instructional principles from the worked examples research. Review of Educational Research, 70, 181-214.

Atkinson, R. K., Catrambone, R., \& Merrill, M. M. (2003). Aiding transfer in statistical learning: Examining the use of conceptually-oriented equations and elaborations. Journal of Education \& Psychology, 95, $762-773$.

Atkinson, R. K., Renkl, A., \& Merrill, M. M. (2003). Transitioning from studying examples to solving problems: Effects of self-explanation prompts and fading worked-out steps. Journal of Education \& Psychology, 95, 774-783.

Ayres, P. (1993). Why goal-free problems can facilitate learning. Contemporary Educational Psychology, 18, 376-381.

Ayres, P., \& Paas, F. (2007). Making instructional animations more effective: A cognitive load approach. Applied Cognitive Psychology, 21, 695-700.

Badets, A., Blandin, Y., Wright, D. L., \& Shea, C. H. (2006). Error detection processes during observational learning. Research Quarterly for Exercise and Sport, 77, 177-184.

Baldwin, T. T. (1992). Effects of alternative modelling strategies on outcomes of interpersonal-skills training. The Journal of Applied Psychology, 77, 147-154.

Bandura, A. (1977). Social learning theory. Englewood Cliffs: Prentice Hall.

Bandura, A. (1986). Social foundations of thought and action: A social cognitive theory. Englewood Cliffs: Prentice Hall.

Bandura, A., \& Kupers, C. J. (1964). Transmission of patterns of self-reinforcement through modeling. Journal of Abnormal and Social Psychology, 69, 1-9.

Bandura, A., Ross, D., \& Ross, S. A. (1963). Imitation of film-mediated aggressive models. Journal of Abnormal and Social Psychology, 66, 3-11.

Barry, N. J., \& Overman, P. B. (1977). Comparison of the effectiveness of adult and peer models with EMR children. American Journal of Mental Deficiency, 82, 33-36.

Bjork, R. A. (1999). Assessing our own competence: Heuristics and illusions. In D. Gopher \& A. Koriat (Eds.), Attention and performance XVII. Cognitive regulation of performance: Interaction of theory and application (pp. 435-459). Cambridge: MITPress. 
Blandin, Y., \& Proteau, L. (2000). On the cognitive basis of observational learning: Development of mechanisms for the detection and correction of errors. The Quarterly Journal of Experimental Psychology, 53A, 846-867.

Blandin, Y., Lhuisset, L., \& Proteau, L. (1999). Cognitive processes underlying observational learning of motor skills. The Quarterly Journal of Experimental Psychology, 52A, 957-979.

Blessing, S., \& Anderson, J. R. (1996). How people learn to skip steps. Journal of Experimental Psychology. Learning, Memory, and Cognition, 22, 576-598.

Boekhout, P., Van Gog, T., Van de Wiel, M., Gerards-Last, D., \& Geraets, J. (in press). Example-based learning: Effects of model expertise in relation to student expertise. British Journal of Educational Psychology.

Braaksma, M. A. H., Rijlaarsdam, G., \& Van den Bergh, H. (2002). Observational learning and the effects of model-observer similarity. Journal of Education \& Psychology, 94, 405-415.

Braaksma, M. A. H., Rijlaarsdam, G., Van den Bergh, H., \& Van Hout-Wolters, B. H. A. M. (2004). Observational learning and its effects on the orchestration of writing processes. Cognition and Instruction, 22, 1-36.

Carroll, W. M. (1994). Using worked out examples as an instructional support in the algebra classroom. Journal of Education \& Psychology, 86, 360-367.

Catrambone, R. (1995). Aiding subgoal learning: Effects on transfer. Journal of Education \& Psychology, 87, 5-17.

Catrambone, R. (1996). Generalizing solution procedures learned from examples. Journal of Experimental Psychology. Learning, Memory, and Cognition, 22, 1020-1031.

Chandler, P., \& Sweller, J. (1991). Cognitive load theory and the format of instruction. Cognition and Instruction, 8, 293-332.

Charlop, M. H., Schreibman, L., \& Tryon, A. S. (1983). Learning through observation: The effects of peer modeling on acquisition and generalization in autistic children. Journal of Abnormal Child Psychology, $11,355-366$.

Chi, M. T. H., Bassok, M., Lewis, M. W., Reimann, P., \& Glaser, R. (1989). Self-explanations: How students study and use examples in learning to solve problems. Cognitive Science, 13, 145-182.

Chi, M. T. H., Roy, M., \& Hausmann, R. G. M. (2008). Observing tutorial dialogues collaboratively: Insights about human tutoring effectiveness from vicarious learning. Cognitive Science, 32, 301-341.

Collins, A., Brown, J. S., \& Newman, S. E. (1989). Cognitive apprenticeship: Teaching the crafts of reading, writing, and mathematics. In L. B. Resnick (Ed.), Knowing, learning, and instruction (pp. 453-494). Hillsdale: Erlbaum.

Cooper, G., \& Sweller, J. (1987). The effects of schema acquisition and rule automation on mathematical problem-solving transfer. Journal of Education \& Psychology, 79, 347-362.

Cooper, G., Tindall-Ford, S., Chandler, P., \& Sweller, J. (2001). Learning by imagining. Journal of Experimental Psychology. Applied, 7, 68-82.

Couzijn, M. (1999). Learning to write by observation of writing and reading processes: Effects on learning and transfer. Learning and Instruction, 9, 109-142.

Craig, S. D., Chi, M. T. H., \& VanLehn, K. (2009). Improving classroom learning by collaboratively observing human tutoring videos while problem solving. Journal of Education \& Psychology, 101, 779-789.

De Koning, B. B., Tabbers, H. K., Rikers, R. M. J. P., \& Paas, F. (2009). Towards a framework for attention cueing in instructional animations: Guidelines for research and design. Educational Psychology Review, $21,113-140$.

Decker, P. J. (1980). Effects of symbolic coding and rehearsal in behavior modeling training. The Journal of Applied Psychology, 65, 627-634.

Decker, P. J. (1984). Effects of different symbolic coding stimuli in behavior modeling training. Personnel Psychology, 37, 711-720.

Driskell, J. E., Copper, C., \& Moran, A. (1994). Does mental practice enhance performance? The Journal of Applied Psychology, 79, 481-492.

Dunning, D., Johnson, K., Erlinger, J., \& Kruger, J. (2003). Why people fail to recognize their own incompetence. Current Directions in Psychological Science, 12, 83-87.

Feldon, D. F. (2007). The implications of research on expertise for curriculum and pedagogy. Educational Psychology Review, 19, 91-110.

Feltz, D. L., \& Landers, D. M. (1983). The effects of mental practice on motor skill learning and performance: A meta-analysis. Journal of Sport Psychology, 5, 25-57.

Fouts, G., \& Click, M. (1979). Effects of live and TV models on observational learning in introverted and extroverted children. Perceptual and Motor Skills, 48, 863-867.

George, T., Feltz, D., \& Chase, M. (1992). Effects of model similarity on self-efficacy and muscular endurance: A second look. Journal of Sport \& Exercise Psychology, 14, 237-248. 
Ginns, P., Chandler, P., \& Sweller, J. (2003). When imagining information is effective. Contemporary Educational Psychology, 28, 229-251.

Grèzes, J., \& Decety, J. (2001). Functional anatomy of execution, mental simulation, observation, and verb generation of actions: A meta-analysis. Human Brain Mapping, 12, 1-19.

Große, C. S., \& Renkl, A. (2006). Effects of multiple solution methods in mathematics learning. Learning \& Instruction, 16, 122-138.

Große, C. S., \& Renkl, A. (2007). Finding and fixing errors in worked examples: Can this foster learning outcomes? Learning and Instruction, 17, 612-634.

Gullberg, M., \& Holmqvist, K. (2002). Visual attention towards gesture in face-to-face interaction vs. on screen. In I. Wachsmuth \& T. Sowa (Eds.), Gesture and sign language based human-computer interaction (pp. 206-214). Berlin: Springer Verlag.

Halpin, G., Halpin, G., Miller, E., \& Landreneau, E. (1979). Observer characteristics related to the imitation of a creative model. Journal of Psychology: Interdisciplinary and Applied, 102, 133-142.

Hilbert, T. S., \& Renkl, A. (2009). Learning how to use a computer-based concept-mapping tool: Selfexplaining examples helps. Computers in Human Behavior, 25, 267-274.

Hinds, P. J., Patterson, M., \& Pfeffer, J. (2001). Bothered by abstraction: The effect of expertise on knowledge transfer and subsequent novice performance. The Journal of Applied Psychology, 86, 12321243.

Hitchcock, C., Dowrick, P., \& Prater, M. (2003). Video self-modeling intervention in school-based settings. Remedial \& Special Education, 24, 36-45.

Hoogveld, A. W. M., Paas, F., \& Jochems, W. M. G. (2005). Training higher education teachers for instructional design of competency-based education: Product-oriented versus process-oriented worked examples. Teaching and Teacher Education, 21, 287-297.

Hurley, S. (2008). The shared circuits model (SCM): How control, mirroring, and simulation can enable imitation, deliberation, and mindreading. The Behavioral and Brain Sciences, 31, 1-58.

Kalyuga, S. (2007). Expertise reversal effect and its implications for learner-tailored instruction. Educational Psychology Review, 19, 509-539.

Kalyuga, S., \& Sweller, J. (2004). Measuring knowledge to optimize cognitive load factors during instruction. Journal of Education \& Psychology, 96, 558-568.

Kalyuga, S., Chandler, P., Tuovinen, J., \& Sweller, J. (2001). When problem solving is superior to studying worked examples. Journal of Education \& Psychology, 93, 579-588.

Kalyuga, S., Ayres, P., Chandler, P., \& Sweller, J. (2003). Expertise reversal effect. Educational Psychologist, $38,23-31$.

Kim, Y. (2007). Desirable characteristics of learning companions. International Journal of Artificial Intelligence in Education, 17, 371-388.

Kirschner, F., Paas, F., \& Kirschner, P. A. (2009). A cognitive load approach to collaborative learning: United brains for complex tasks. Educational Psychology Review, 21, 31-42.

Kirschner, F., Paas, F., Kirschner, P. A., \& Janssen, J. (2010). Effects of instructional format on individual and collaborative learning efficiency: Solving conventional problems versus studying worked examples. Manuscript submitted for publication.

Kitsantas, A., Zimmerman, B. J., \& Cleary, T. (2000). The role of observation and emulation in the development of athletic self-regulation. Journal of Education \& Psychology, 92, 811-817.

Koedinger, K. R., \& Aleven, V. (2007). Exploring the assistance dilemma in experiments with cognitive tutors. Educational Psychology Review, 19, 239-264.

Kopp, V., Stark, R., \& Fischer, M. R. (2008). Fostering diagnostic knowledge through computer-supported, casebased worked examples: Effects of erroneous examples and feedback. Medical Education, 42, 823-829.

Kuhn, G., Tatler, B. W., Findlay, J. M., \& Cole, G. G. (2008). Misdirection in magic: Implications for the relationship between eye gaze and attention. Visual Cognition, 16, 391-405.

Leahy, W., \& Sweller, J. (2005). Interactions among the imagination, expertise reversal and element interactivity effects. Journal of Experimental Psychology. Applied, 11, 266-276.

Leahy, W., \& Sweller, J. (2008). The imagination effect increases with an increased intrinsic cognitive load. Applied Cognitive Psychology, 22, 273-283.

Louwerse, M. M., Graesser, A. C., McNamara, D. S., \& Lu, S. (2009). Embodied conversational agents as conversational partners. Applied Cognitive Psychology, 23, 1244-1255.

Lovett, M. C. (1992). Learning by problem solving versus by examples: The benefits of generating and receiving information. Proceedings of the 14th annual conference of the Cognitive Science Society (pp. 956-961). Hillsdale: Erlbaum.

Mayer, R. E. (2005). Principles of multimedia learning based on social cues: Personalization, voice, and image principles. In R. E. Mayer (Ed.), The Cambridge handbook of multimedia learning (pp. 201-212). New York: Cambridge University Press. 
McGivern, J., Levin, J., Ghatala, E., \& Pressley, M. (1986). Can selection of an effective memory strategy be induced vicariously? Contemporary Educational Psychology, 11, 170-186.

McLaren, B. M., Lim, S., Gagnon, F., Yaron, D., \& Koedinger, K. R. (2006). Studying the effects of personalized language and worked examples in the context of a web-based intelligent tutor. In M. Ikeda, K. D. Ashley, \& T.-W. Chan (Eds.), Intelligent tutoring systems 2006, lecture notes in computer science 4053 (pp. 318-328). Berlin: Springer.

McLaren, B. M., Lim, S., \& Koedinger, K. R. (2008). When and how often should worked examples be given to students? New results and a summary of the current state of research. In B. C. Love, K. McRae, \& V. M. Sloutsky (Eds.), Proceedings of the 30th Annual Conference of the Cognitive Science Society (pp. 2176-2181). Austin: Cognitive Science Society.

Miller, N., \& Dollard, J. (1941). Social learning and imitation. New Haven: Yale University Press.

Mousavi, S. Y., Low, R., \& Sweller, J. (1995). Reducing cognitive load by mixing auditory and visual presentation modes. Journal of Education \& Psychology, 87, 319-334.

Mwangi, W., \& Sweller, J. (1998). Learning to solve compare word problems: The effect of example format and generating self-explanations. Cognition and Instruction, 16, 173-199.

Nievelstein, F., Van Gog, T., Van Dijck, G., \& Boshuizen, H. P. A. (2010). The worked example and expertise reversal effect in less structured tasks: Learning to reason about legal cases. Manuscript submitted for publication.

Olson, R., Grosshuesch, A., Schmidt, S., Gray, M., \& Wipfli, B. (2009). Observational learning and workplace safety: The effects of viewing the collective behavior of multiple social models on the use of personal protective equipment. Journal of Safety Research, 40, 383-387.

Osman, M. (2008). Observation can be as effective as action in problem solving. Cognitive Science, 32, 162183.

Paas, F. (1992). Training strategies for attaining transfer of problem-solving skill in statistics: A cognitive load approach. Journal of Education \& Psychology, 84, 429-434.

Paas, F., \& Van Merriënboer, J. J. G. (1994). Variability of worked examples and transfer of geometrical problem-solving skills: A cognitive-load approach. Journal of Education \& Psychology, 86, 122-133.

Paas, F., Camp, G., \& Rikers, R. (2001). Instructional compensation for age-related cognitive declines: Effects of goal specificity in maze learning. Journal of Education \& Psychology, 93, 181-186.

Quilici, J. L., \& Mayer, R. E. (1996). Role of examples in how students learn to categorize statistics word problems. Journal of Education \& Psychology, 88, 144-161.

Reed, S. K., Willis, D., \& Guarino, J. (1994). Selecting examples for solving word problems. Journal of Education \& Psychology, 86, 380-388.

Reisslein, J., Atkinson, R. K., Seeling, P., \& Reisslein, M. (2006). Encountering the expertise reversal effect with a computer-based environment on electrical circuit analysis. Learning and Instruction, 16, 92-103.

Renkl, A. (1997). Learning from worked-out examples: A study on individual differences. Cognitive Science, 21, 1-29.

Renkl, A. (2002). Learning from worked-out examples: Instructional explanations supplement selfexplanations. Learning \& Instruction, 12, 149-176.

Renkl, A., \& Atkinson, R. K. (2003). Structuring the transition from example study to problem solving in cognitive skills acquisition: A cognitive load perspective. Educational Psychologist, 38, 15-22.

Renkl, A., Atkinson, R. K., Maier, U. H., \& Staley, R. (2002). From example study to problem solving: Smooth transitions help learning. Journal of Experimental Education, 70, 293-315.

Renkl, A., Hilbert, T., \& Schworm, S. (2009). Example-based learning in heuristic domains: A cognitive load theory account. Educational Psychology Review, 21, 67-78.

Rikers, R. M. J. P., Boshuizen, H. P. A., \& Schmidt, H. G. (2000). Knowledge encapsulation and the intermediate effect. Contemporary Educational Psychology, 25, 150-166.

Ringenberg, M. A., \& VanLehn, K. (2006). Scaffolding problem solving with annotated worked-out examples to promote deep learning. In M. Ikeda, K. D. Ashley, \& T.-W. Chan (Eds.), Intelligent tutoring systems 2006, lecture notes in computer science 4053 (pp. 625-634). Berlin: Springer.

Rittle-Johnson, B., Star, J. R., \& Durkin, K. (2009). The importance of prior knowledge when comparing examples: Influences on conceptual and procedural knowledge of equation solving. Journal of Education \& Psychology, 101, 836-852.

Rizzolatti, G., \& Craighero, L. (2004). The mirror-neuron system. Annual Review of Neuroscience, 27, 169192.

Rourke, A., \& Sweller, J. (2009). The worked-example effect using ill-defined problems: Learning to recognize designers' styles. Learning and Instruction, 19, 185-199.

Rummel, N., \& Spada, H. (2005). Learning to collaborate: An instructional approach to promoting collaborative problem-solving in computer-mediated settings. Journal of the Learning Sciences, 14, 201-241. 
Rummel, N., Spada, H., \& Hauser, S. (2009). Learning to collaborate while being scripted or by observing a model. International Journal of Computer-Supported Collaborative Learning, 4, 69-92.

Schunk, D. H. (1981). Modeling and attributional effects on children's achievement: A self-efficacy analysis. Journal of Education \& Psychology, 73, 93-105.

Schunk, D. H. (1987). Peer models and children's behavioral change. Review of Educational Research, 57, $149-174$

Schunk, D. H., \& Hanson, A. R. (1985). Peer models: Influence on children's self-efficacy and achievement. Journal of Education \& Psychology, 77, 313-322.

Schunk, D., \& Hanson, A. (1989). Self-modeling and children's cognitive skill learning. Journal of Education \& Psychology, 81, 155-163.

Schunk, D. H., Hanson, A. R., \& Cox, P. D. (1987). Peer-model attributes and children's achievement behaviors. Journal of Education \& Psychology, 79, 54-61.

Schwonke, R., Renkl, A., Krieg, C., Wittwer, J., Aleven, V., \& Salden, R. J. C. M. (2009). The workedexample effect: Not an artefact of lousy control conditions. Computers in Human Behavior, 25, 258-266.

Schworm, S., \& Renkl, A. (2007). Learning argumentation skills through the use of prompts for selfexplaining examples. Journal of Education \& Psychology, 99, 285-296.

Shea, C. H., Wright, D. L., Wulf, G., \& Whitacre, C. (2000). Physical and observational practice afford unique learning opportunities. Journal of Mot. Behavior, 32, 27-36.

Simon, S. J., \& Werner, J. M. (1996). Computer training through behavior modeling, self-paced, and instructional approaches: A field experiment. The Journal of Applied Psychology, 81, 648-659.

Spanjers, I., Van Gog, T., \& Van Merriënboer, J. J. G. (in press). A theoretical analysis of how segmentation of dynamic visualizations enhances students' learning. Educational Psychology Review.

Spanjers, I. A. E., Wouters, P., Van Gog, T., \& Van Merriënboer, J. J. G. (in press). An expertise reversal effect of segmentation in learning from animated worked-out examples. Computers in Human Behavior.

Sweller, J. (1988). Cognitive load during problem-solving: Effects on learning. Cognitive Science, 12, 257-285.

Sweller, J. (2004). Instructional design consequences of an analogy between evolution by natural selection and human cognitive architecture. Instructional Science, 32, 9-31.

Sweller, J. (this issue). Element interactivity and intrinsic, extraneous and germane cognitive load. Educational Psychology Review.

Sweller, J., \& Cooper, G. A. (1985). The use of worked examples as a substitute for problem solving in learning algebra. Cognition and Instruction, 2, 59-89.

Sweller, J., \& Levine, M. (1982). Effects of goal specificity on means-ends analysis and learning. Journal of Experimental Psychology. Learning, Memory, and Cognition, 8, 463-474.

Sweller, J., \& Sweller, S. (2006). Natural information processing systems. Evolutionary Psychology, 4, 434-458.

Sweller, J., Van Merriënboer, J. J. G., \& Paas, F. (1998). Cognitive architecture and instructional design. Educational Psychology Review, 10, 251-295.

Tarmizi, R., \& Sweller, J. (1988). Guidance during mathematical problem solving. Journal of Education \& Psychology, 80, 424-436.

Tettamanti, M., Buccino, G., Saccuman, M. C., Gallese, V., Danna, M., Scifo, P., et al. (2005). Listening to action-related sentences activates fronto-parietal motor circuits. Journal of Cognitive Neuroscience, 17, 273-281.

Tuovinen, J. E., \& Sweller, J. (1999). A comparison of cognitive load associated with discovery learning and worked examples. Journal of Education \& Psychology, 91, 334-341.

Van Gerven, P. W. M., Paas, F., Van Merriënboer, J. J. G., \& Schmidt, H. G. (2002). Cognitive load theory and aging: Effects of worked examples on training efficiency. Learning and Instruction, 12, 87-105.

Van Gog, T., Paas, F., \& Van Merriënboer, J. J. G. (2006). Effects of process-oriented worked examples on troubleshooting transfer performance. Learning and Instruction, 16, 154-164.

Van Gog, T., Paas, F., \& Van Merriënboer, J. J. G. (2008). Effects of studying sequences of process-oriented and product-oriented worked examples on troubleshooting transfer efficiency. Learning and Instruction, $18,211-222$.

Van Gog, T., Jarodzka, H., Scheiter, K., Gerjets, P., \& Paas, F. (2009a). Attention guidance during example study via the model's eye movements. Computers in Human Behavior, 25, 785-791.

Van Gog, T., Paas, F., Marcus, N., Ayres, P., \& Sweller, J. (2009b). The mirror-neuron system and observational learning: Implications for the effectiveness of dynamic visualizations. Educational Psychology Review, 21, 21-30.

Van Gog, T., Kester, L., \& Paas, F. (2010). Effects of worked examples, example-problem, and problemexample pairs on novices' learning. Manuscript submitted for publication.

Van Gog, T., Kostons, D., \& Paas, F. (in press). Teaching students self-assessment and task-selection skills with video-based modeling examples. Proceedings of the 32nd Annual Conference of the Cognitive Science Society. 
Van Loon-Hillen, N. H., Van Gog, T., \& Brand-Gruwel, S. (in press). Effects of worked examples in a primary school mathematics curriculum. Interactive Learning Environments.

Van Merriënboer, J. J. G. (1997). Training complex cognitive skills: A four-component instructional design model for technical training. Englewood Cliffs: Educational Technology Publications.

Van Merriënboer, J. J. G., \& Sweller, J. (2005). Cognitive load theory and instructional design: Recent developments and future directions. Educational Psychology Review, 17, 147-177.

Van Merriënboer, J. J. G., Schuurman, J. G., De Croock, M. B. M., \& Paas, F. (2002). Redirecting learners' attention during training: Effects on cognitive load, transfer test performance and training. Learning and Instruction, 38, 11-39.

Van Schie, H. T., Mars, R. B., Coles, M. G. H., \& Bekkering, H. (2004). Modulation of activity in medial frontal and motor cortices during error observation. Nature Neuroscience, 7, 549-554.

Ward, M., \& Sweller, J. (1990). Structuring effective worked examples. Cognition and Instruction, 7, 1-39.

Weeks, D. L., \& Anderson, L. P. (2000). The interaction of observational learning with overt practice: Effects on motor skill learning. Acta Psychologica, 104, 259-271.

Weeks, D., Borrousch, S., Bowen, A., Hepler, L., Osterfoss, M., Sandau, A., et al. (2005). The influence of age and gender of an exercise model on self-efficacy and quality of therapeutic exercise performance in the elderly. Physiotherapy Theory \& Practice, 21, 137-146.

Wouters, P., Paas, F., \& Van Merriënboer, J. J. G. (2008). How to optimize learning from animated models: A review of guidelines based on cognitive load. Review of Educational Research, 78, 645-675.

Wouters, P., Paas, F., \& Van Merriënboer, J. J. G. (2009). Observational learning from animated models: Effects of modality and reflection on transfer. Contemporary Educational Psychology, 34, 1-8.

Wright, D. L., Li, Y., \& Coady, W. (1997). Cognitive processes related to contextual interference and observational learning: A replication of Blandin, Proteau and Alain (1994). Research Quarterly for Exercise and Sport, 68, 106-109.

Zimmerman, B. J., \& Kitsantas, A. (2002). Acquiring writing revision and self-regulatory skill through observation and emulation. Journal of Education \& Psychology, 94, 660-668. 